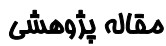

\section{بررسى سرعت خدمات رسانى در بخش اورزانس بيمارستان هاى تابعه دانشكاه

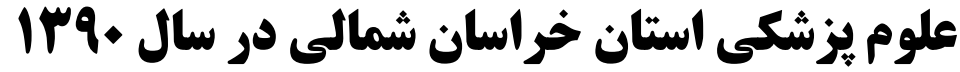

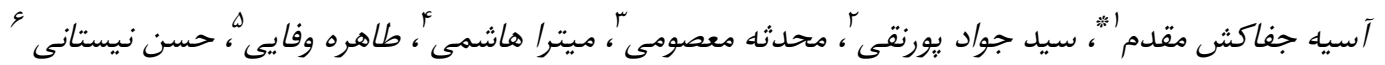

\author{
'كارشناس يرستارى، معاونت درمان دانشگاه علوم يزشكى خراسان شمالى، بجنورد، ايران

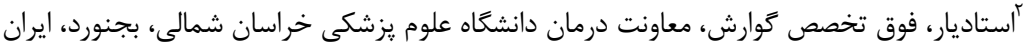

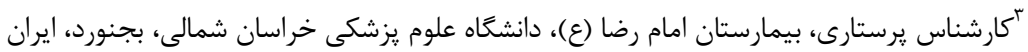

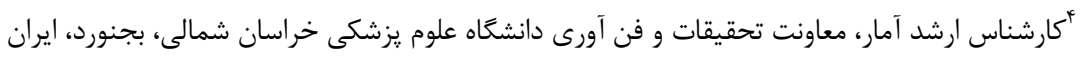

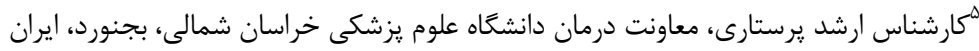

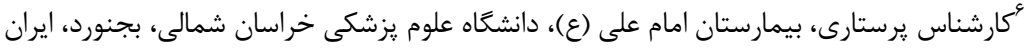

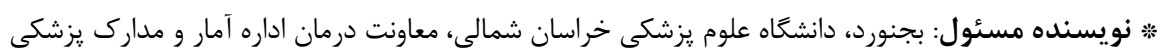

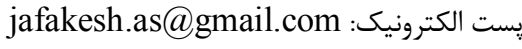 \\ وصول:91/11/11 اصلاح:91/ 9 / 9 يذيرش:
}

קكيده

زمينه و هدف: سرعت /رائه خدمات در اورزانس در جهت كاستن از مرك و مير از اهميت ويزه اى برخوردار است. اتر مدت زمان كردش

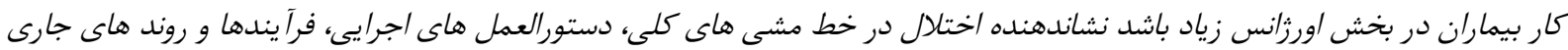

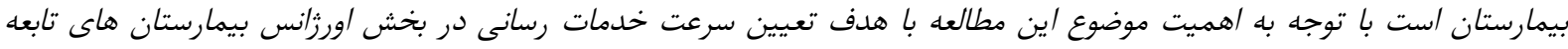

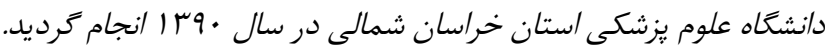

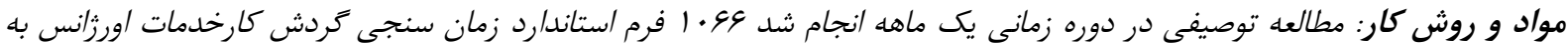
روش نمونه كيرى تصادفى طبقه بندى متناسب انتخاب كرديد. تجزيه و تحليل داده ها با استفاده از نرم افزار يك طرفه انجام شد.

يافته ها: در پِنج بيمارستان مورد مطالعه ميانغين فاصله ورود بيمار به اتاق يزشك تا شروع معاينات و دقيقه، ميانغين زمان اولين اقدام

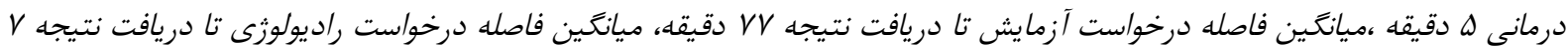

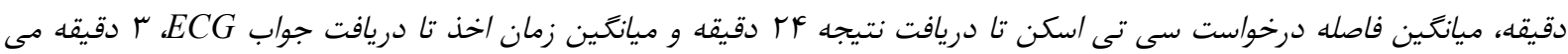

نتيجهكيرى: اكثر شاخص هاى مورد بررسى سرعت خدمات رسانى خوبى داشتند اما زمان براى آماده شدن نتايج آزمايشات كمى با

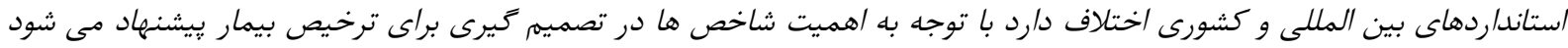

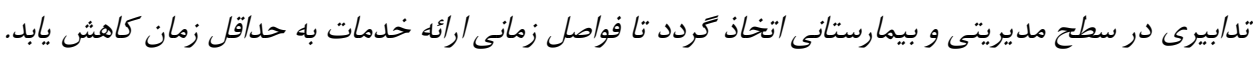

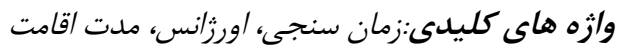

خدمات درمانى به بيمارانى است كه در شرايط مختلف و مقدمه وضعيت هاى اضطرارى و غير اضطرارى شخصا يا به طرق بـ يكى از مهرم ترين بخش هاى بيمارستان كه عملكرد آن مختلف به اين واحد مراجعه مى كنند [r [ ] . هدف اصلى تاثير فراوانى بر عملكرد ساير بخش هاى بيمارستان و سيستم اورزانس انجام سريع و دقيق اقدامات درمانى مرانى رضايت بيماران دارد بخش اورزانس است [ [1] ـ عملكرد صحيح به جاى تلاش براى رسيدن به تشخيص دقيق مى اصلى بخش اورزانس يذيرش، تثبيت وضعيت و ارائه 
بدين منظور در اكثر مراكز اورزانس مدت زمان انتظار بيمار از زمان ورود به اين بخش تا ترخيص از آن آن را به انه

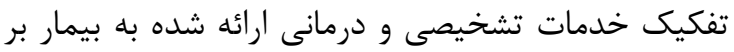

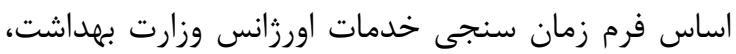

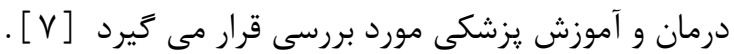
تعداد روزهاى بسترى بك بيمار در بيمارستان از زمان يذيرش تا هنكام ترخيص مدت اقامت ناميده مى شود بدان

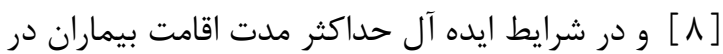

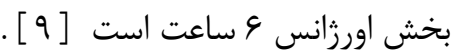
مطالعات نشان مى دهد اخر مدت زمان كَردش كار بيماران در بخش اورزانس زياد باشد نشاندهنده اختلال در خط مدان كردان مشى هاى كلى، دستورالعمل هاى اجرايى، فرآيندها و روند هاى جارى بيمارستان است بطورى كه در بيمارستان

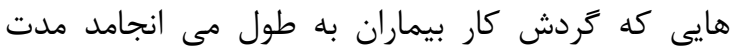

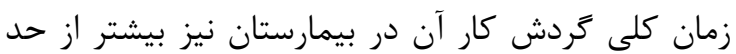

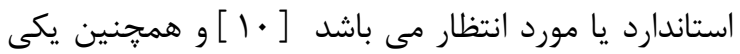

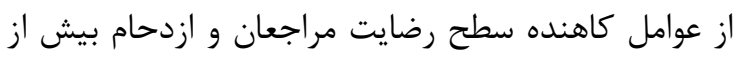

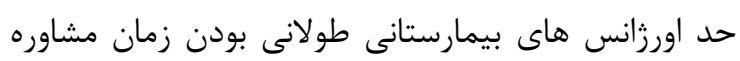
هاى ارائه شده به كَروه هاى درمانى بيمارستانى است

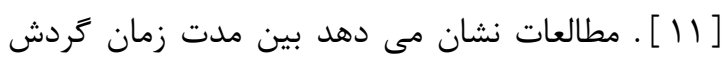

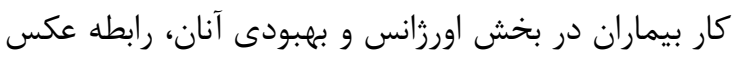

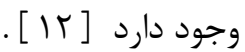
از اين رو با توجه به اهميت موضوع اين مطالعه با هدف دارف آل

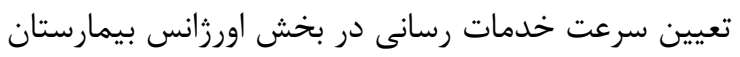
هاى تابعه دانشخاه علوم يزشكى استان خراسان شمان درالى در

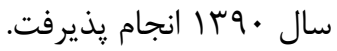

اين مطالعه از نوع توصيفى مى بار باشد كه در يك دوره

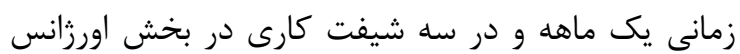
تمامى بيمارستان هاى تابعه دانشكاه علوم يزشكى استان

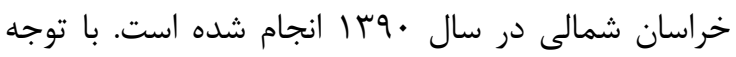
به زياد بودن بار مراجعات ترياز شده حجم نمونه با دان

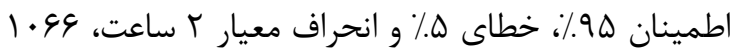

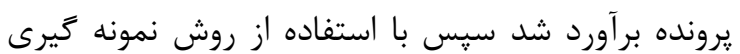
تصادفى طبقه بندى متناسب و با توجه به تعداد بيمار

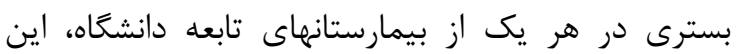

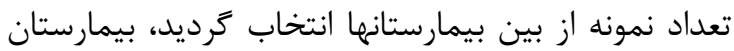

باشد جرا كه همواره اقدامات اوليه درمانى در بيمار اورزانس اولويت دارد [ [r] و اكر بيمارى در لحظات اول و ابتداى ورود به بيمارستان به خوبى بررسى و درمان نشود شايد وجود بخش هاى فوق تخصصى خيلى پيشرفته نيز

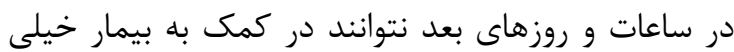

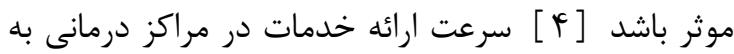

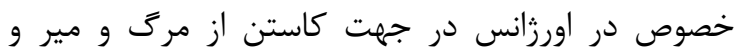

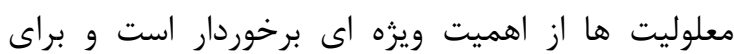
دستيابى به اين هدف اولين كام ترياز صحيح و جامع بيمار

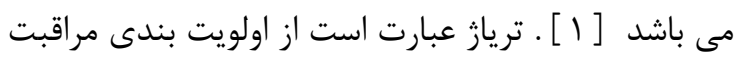
از بيماران بر اساس شدت آسيب و انجام بهترين اقدام درمانى براى بيشترين افراد در كمترين زمان. ترياز به عنوان فعاليت مديريتى قوى در ارايه خدمات درات دران

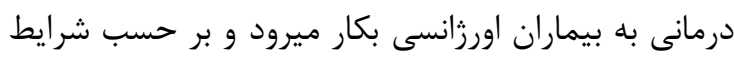

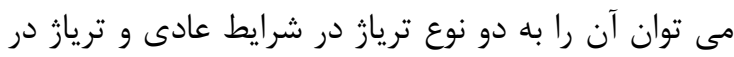

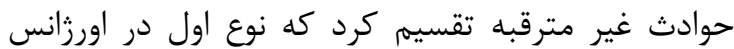

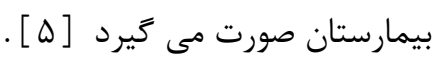

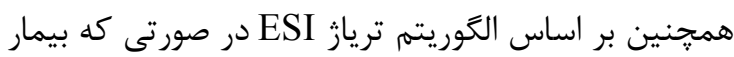
نياز به اقدام فورى و نجات دهنده حيات دارد در سطح يك و در صورتى كه بيمار نبايد جهت دريافت خدمات

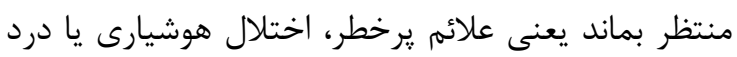

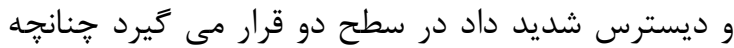
بيمار در حال مرى نباشد و علائم زر خطر هم نداشته

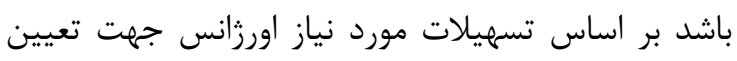

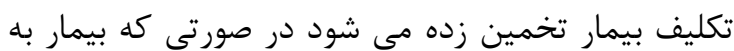
دو يا بيشتر از تسهيلات اورزانس و در صورت عدم اختلال

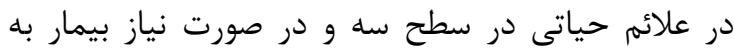

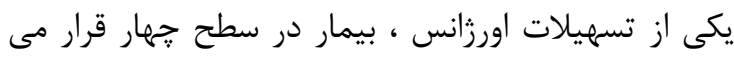
كيرد و بيمارى كه نياز به استفاده از تسهيلات اورزانس

$$
\text { ندارد در سطح ينج قرار مى گيرد. }
$$

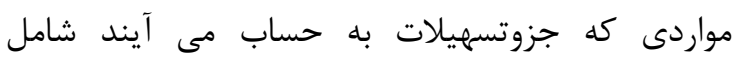

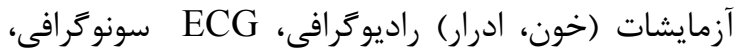

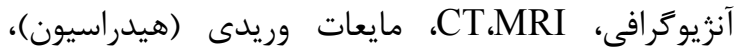
داروهاى اليا نبولايزر، مشاوره تخصصى يروسيجر

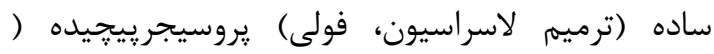
conscious sedation 
به خود اختصاص داد . در اين بين هـآ از مراجعه

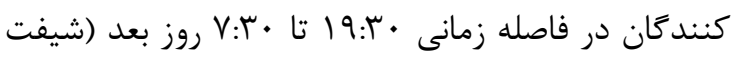

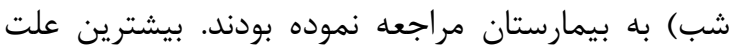

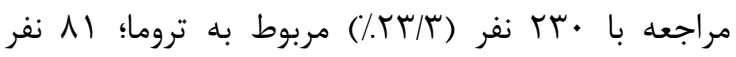

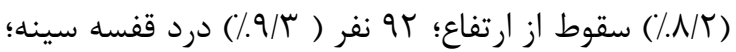

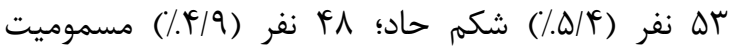
دارويى بوده و كمترين علت مراجعه مربوط به ايكتر ها نفر

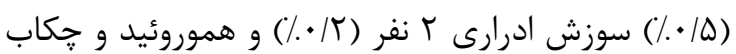

$$
\text { هر كدام / • • بود. }
$$

با توجه به تعاريف سطح بندى بخش اورزانس در

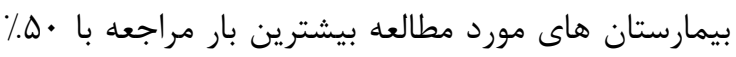

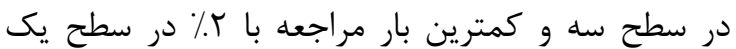

بودند.( نمودار () )

همجنين نتايج نشان داد در ينج بيمارستان مورد مطالعه ميانكَين فاصله بين ورود بيمار به اتاق بزشك تا شروع بنان معاينات \& دقيقه، ميانگين زمان اولين اقدام درمانى هـ

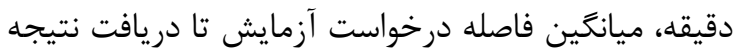

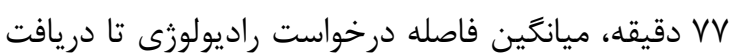
نتيجه V دقيقه، فاصله دريافت سى تى اسكن تا دريافت

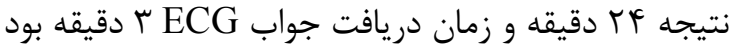

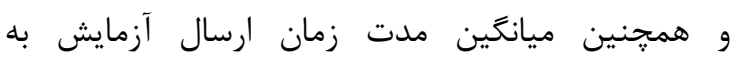

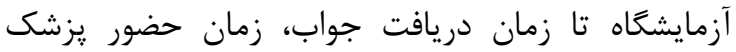
مشاور بر بالين بيمار، مدت زمان مشاوره تلفنى، فاصله

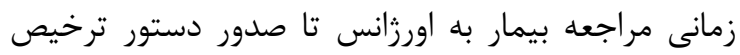

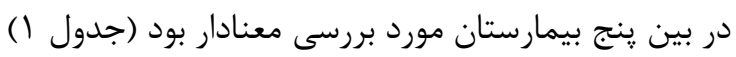
بين مدت زمان دريافت جواب آزمايشات و سطح بندى بدى بدان

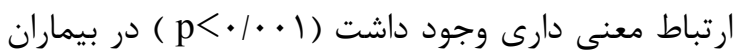

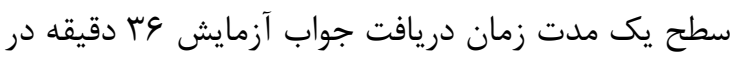

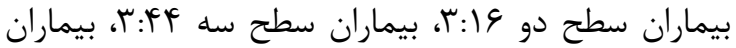

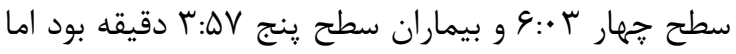

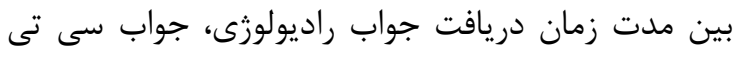
اسكن و جواب ECG ارتباط معنادارى وجود نداشت. بين مدت زمان دريافت مشاوره حضورى و سطح بندى

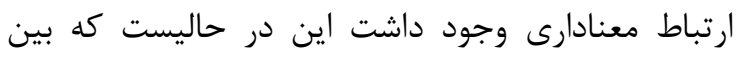

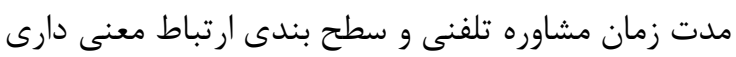

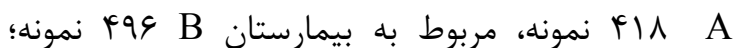
بيمارستان VF C نمونه؛ بيمارستان SV D نمونه بونان و 11 نمونه مربوط به بيمارستان E (بودند.

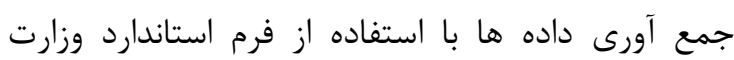
بهداشت، درمان و آموزش يزشكى تحت عنوان زمان زمان سنجى گردش كارخدمات اورزانس، انجام يذيرفت. اين فرمان شامل آيتم هاى ترياز بيمار، يزشك مقيم، اقدامات

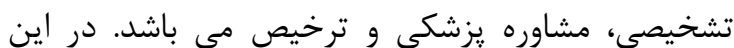
ينج آيتم به موارد جنسيت مراجعه كننده، سطح بندى،

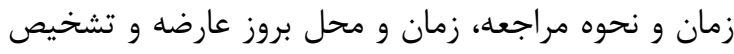
اوليه، زمان اولين ويزيت، شروع اولين اقدام درمان دمانى، زمان زمان اقدامات آزمايشكاهى و راديولوزى و دريافت نتايج آنها، زمان اقدامات مشاوره يزشكى در صورت لزوم و زمان ترخيص بيمار از اورزانس و يا انتقال وى به ساير قسمت دمان هاى درمانى مى يردازد. براى جمع آورى داده ها از يزوهشكر آشنا به فرآيند ترياز

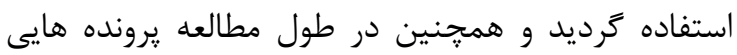
كه اطلاعات ثبت شده ناقص داشتند از مطالعه حذف درد

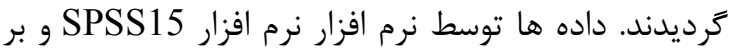

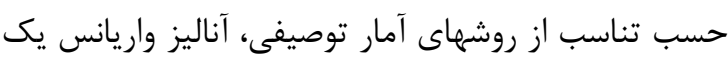

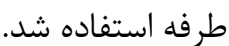

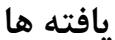
از 94. أفرم ترياز بيماران مراجعه كننده به اورزانس در ينج بيمارستان تابعه دانشكاه علوم يزشكى خراسان شمالى درانى

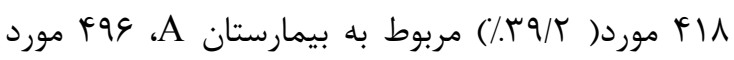

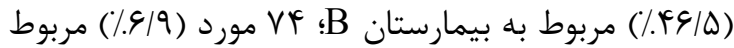

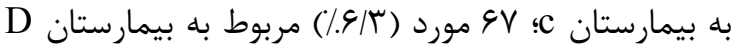

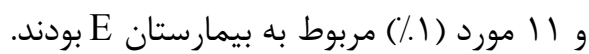

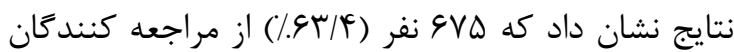
به اورزانس مرد و بقيه زن بودند. نحوه مراجعه بيماران در

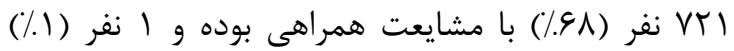

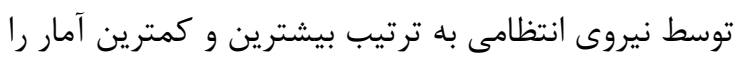

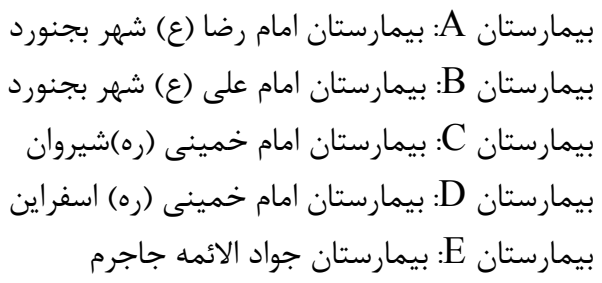




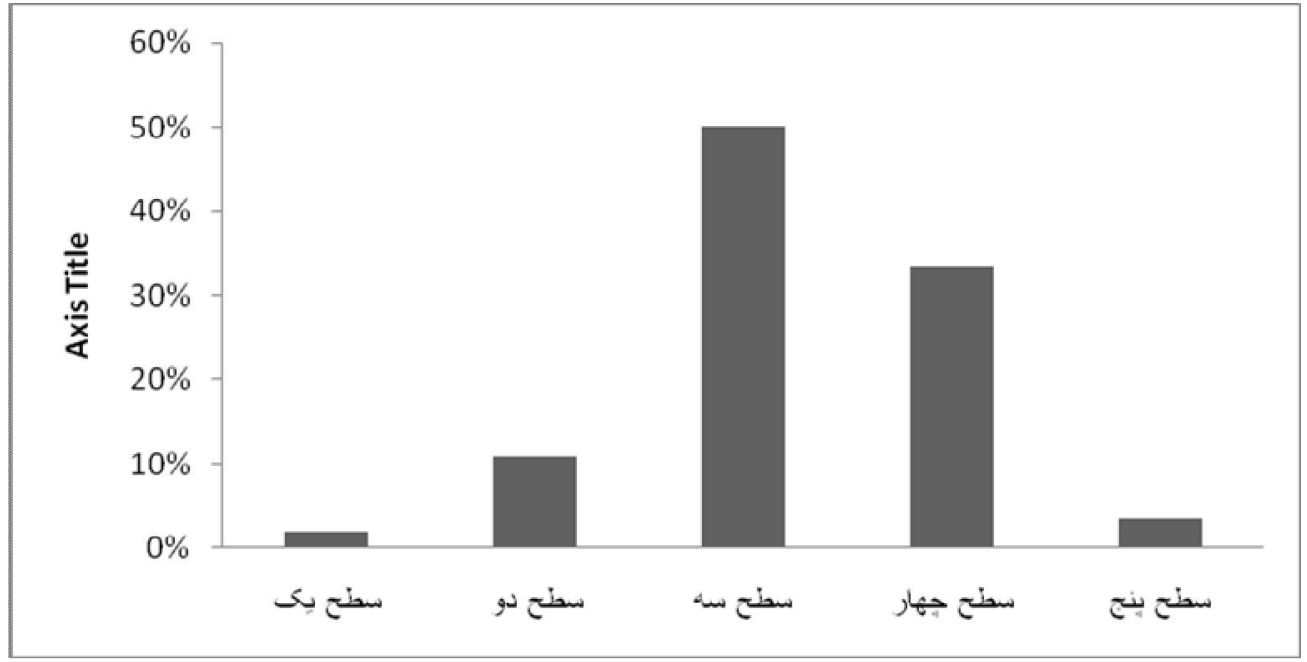

نمودار ا: توزيع فراوانى مراجعات بيماران به اورزانس بر اساس سطح بندى

جدول ا: ميانگين شاخص ها در بين ينج بيمارستان مورد مطالعه

\begin{tabular}{|c|c|c|c|}
\hline بيشترين ميانكين & كمترين ميانگين & P Value & شاخص \\
\hline بيمارستان A & بيمارستان D & \multirow[t]{2}{*}{$\mathrm{P}<\bullet / \bullet 1$} & \multirow[t]{2}{*}{ ارسال آزمايش به آزمايشكاه تا زمان دريافت جواب } \\
\hline$r: f \Delta \pm r: 1 \Delta$ & |r: & & \\
\hline 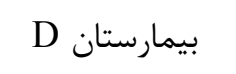 & 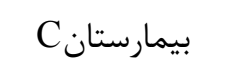 & \multirow[t]{2}{*}{$\mathrm{P}<\bullet / \bullet 1$} & \multirow{2}{*}{ زمان حضور يزشك مشاور بر بالين بيمار } \\
\hline$r: r \mu \pm 1: r$. & $\cdot: \Delta Y \pm \cdot: Y Y$ & & \\
\hline بيمارستان B & بيمارستان E & \multirow[t]{2}{*}{$\mathrm{P}<\bullet / \bullet$} & \multirow[t]{2}{*}{ مدت زمان مشاوره تلفنى } \\
\hline r:T & $\cdot: \bullet \vee \pm \cdot: \bullet \vee$ & & \\
\hline Eيمارستان E & A بيمارستان & $\mathrm{P}<\bullet / \bullet 1$ & \multirow{4}{*}{ 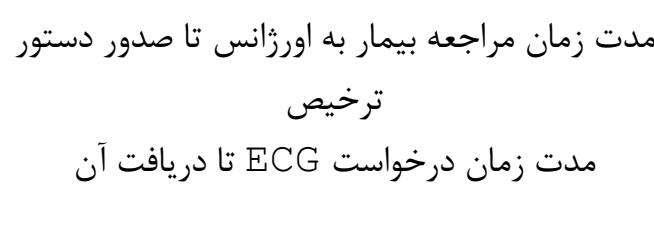 } \\
\hline $1: 1 \wedge \pm \cdot: \uparrow \Delta$ & $\varepsilon_{: \cdot \cdot \pm r: r}$ & & \\
\hline 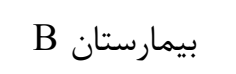 & A بيمارستان & $\mathrm{P}<\bullet / \bullet)$ & \\
\hline$\cdot: 1 \wedge \pm \cdot: 1 \Upsilon$ & $\cdot: \cdot 1 \pm \cdot: \cdot 1$ & & \\
\hline
\end{tabular}

جدول ז: توزيع فراوانى مراجعه كنند

\begin{tabular}{|c|c|c|}
\hline درصد & فراوانى & وضعيت بيمار \\
\hline$\% . \Delta V / G$ & 9.9 & ترخيص \\
\hline$\%$ Tr & MYl & بسترى \\
\hline$\% / T / F$ & $r \Delta$ & اعزام \\
\hline$\% \cdot 1 \wedge$ & $\wedge$ & ارجاع به مطب يزشك \\
\hline$\%$ \%/ & TV & اتاق عمل \\
\hline$\% / \Lambda$ & f. & ترخيص با رضايت شخصى \\
\hline$\% \cdot / V$ & v & فوت \\
\hline
\end{tabular}


متوسط •و تا •V دقيقه نتايج نسبتا مشابهى داشته و

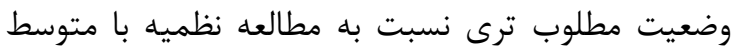
9.1 دقيقه داشت اين در حاليست كه بر اساس بـ بـ استانداردهاى انجمن اورزانس امريكا زمان صرف شده بين

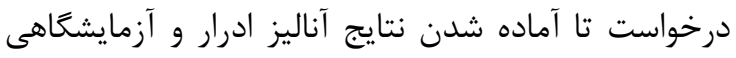
بيوشيمى خون حداكثر •9 دقيقه ييش بينى شده است. [ ه 1 ] كه نشان دهنده اتلاف زمان براى آماده شدن نتايج

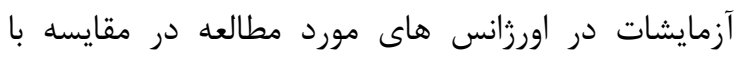
استانداردهاى بين المللى مى باشد.

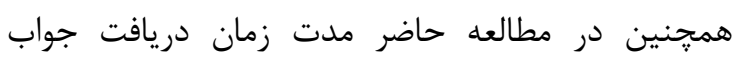

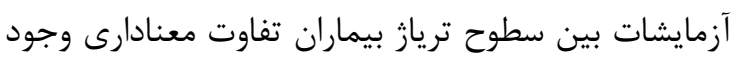

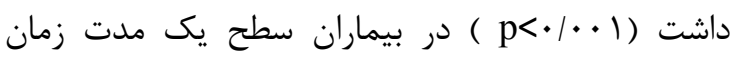

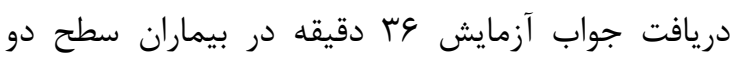

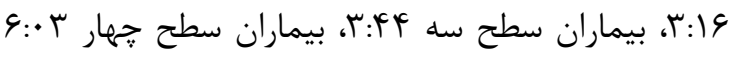
بود (مدت زمان دريافت جواب آزمايشات در سطح ينج

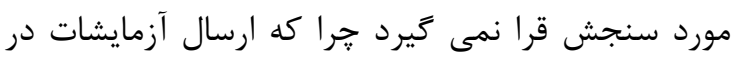
اورزانس جزء تسهيلات بوده و نياز به آن بيمار را در سطح

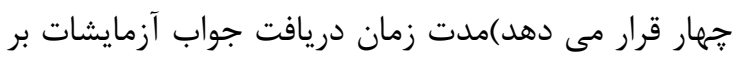
اساس سطح بندى بيانكر اين است كه با توجه به اينكه

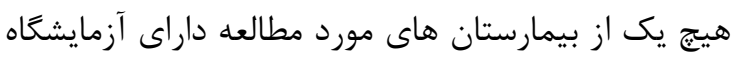

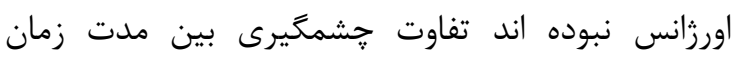
دريافت جواب آزمايش در بيماران سطح يك با ساير

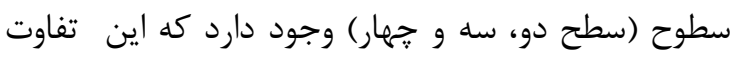
مى تواند به دليل پيخيرى مرتب جواب آزمايشات بيماران سطح يك، توسط يرسنل يرستارى باشد.

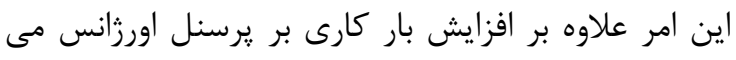

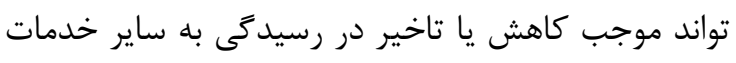

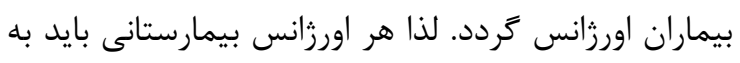
آزمايشگاه اورزانس مجهز بوده تا اين خدمات درات در همان

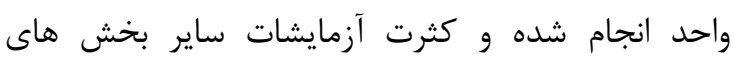

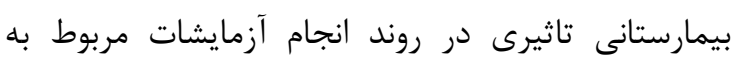
بيماران اورزانس نداشته باشد.

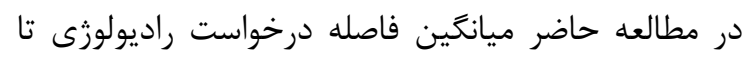
دريافت نتيجه V دقيقه، فاصله دريافت سى تى اسكن تا داصن

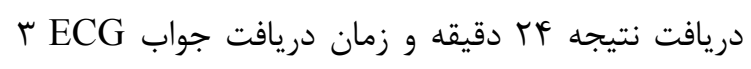

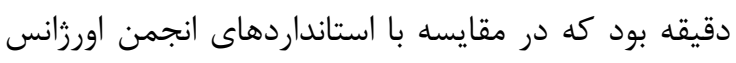

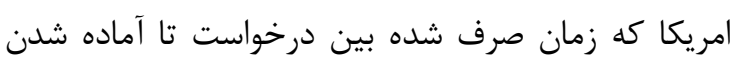

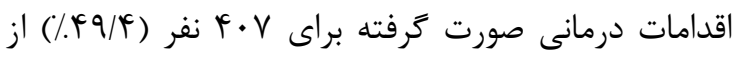
مراجعه كنند

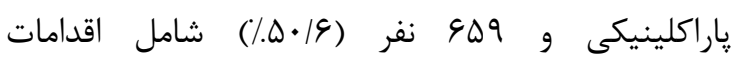

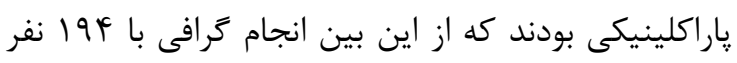

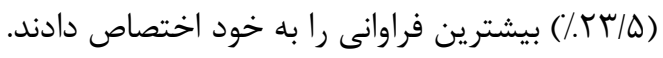

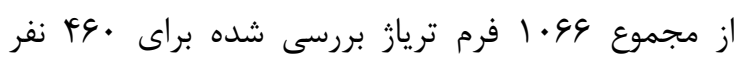

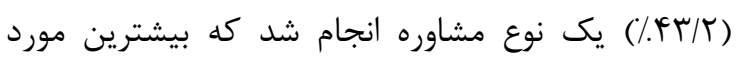

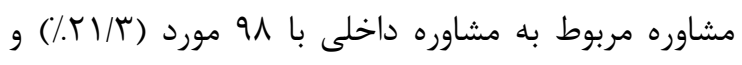

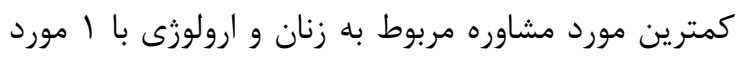

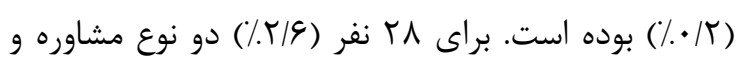

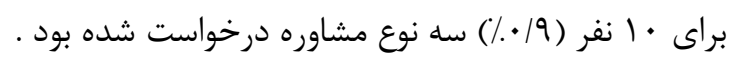

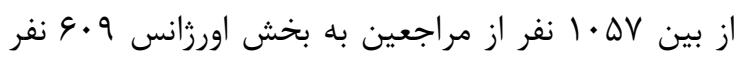

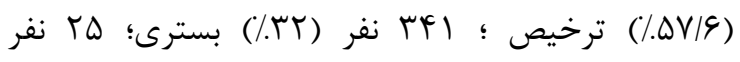

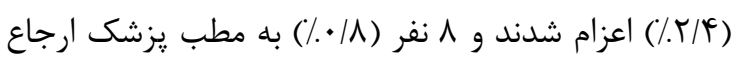

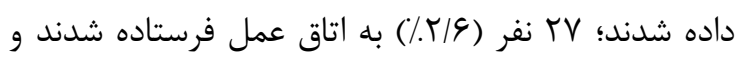

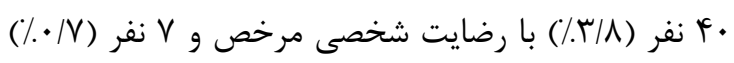

فوت شدند. (جدول r)

بحث

در ينج بيمارستان مورد مطالعه ميانگين فاصله بين ترياز

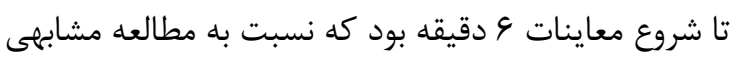

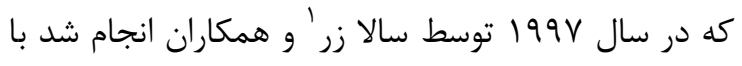

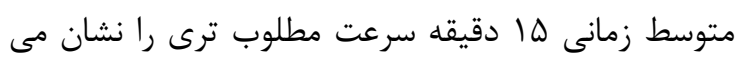

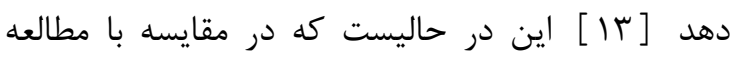

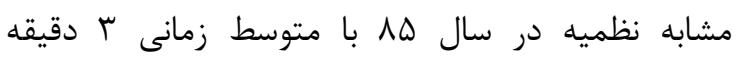

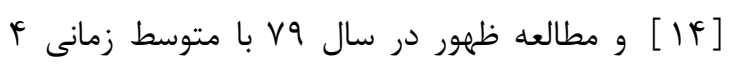
دقيقه [ [ ] از اتلاف زمان بيشترى در فاصله بين ترياز تا

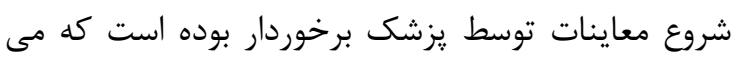
تواند ناشى از مجزا نبودن فضاى فيزيكى درمانكاه بيماران

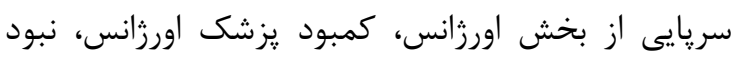

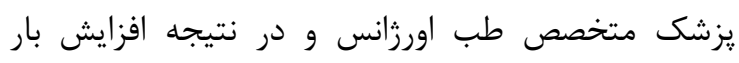
مراجعات به يزشك اورزانس بوده باشد.

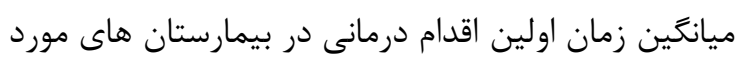

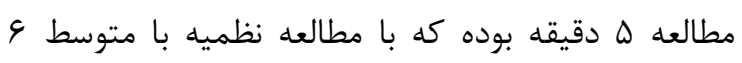

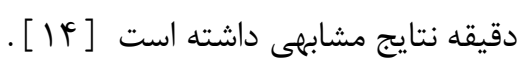

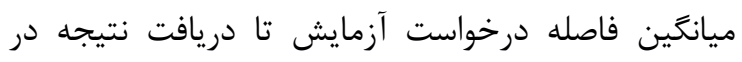

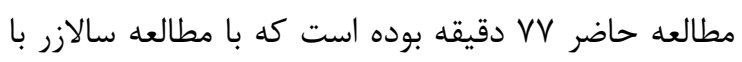




\section{نتيجه كيرى}

مقايسه يافته هاى يزوهشى با استانداردهاى بين المللى نشان مى دهد تعدادى از شاخص ها از جمله زمان اولين

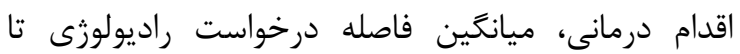
دريافت نتيجه، فاصله دريافت سى تى اسكن تا دريافت نتيجه ،زمان دريافت جواب ECG از سرعت خدمات رسانى خوبى برخوردار هستند اما زمان تلف شده براى آماده شدن نتايج آزمايشات در اورزانس هاى مورد مورد مطالعه

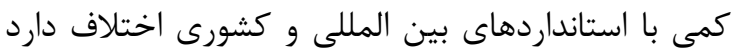
همانطور كه در بحث به آن يرداخته شد اين امر مى تواند به ضرورت وجود آزمايشگاه اورزانس در فضاى فيزيكى هر نهر اورزانس بيمارستانى اشاره نمايد. همجنين با توجه به به اينكه اين شاخص ها در تصميم گيرى براى ترخيص بيمار حائز اهميت هستند ييشنهاد مى شود تدابيرى در سطح مديريتى و بيمارستانى اتخاذ گردد تا فواصل زمانى ارائه خدمات به حداقل زمان كاهش يابد.

$$
\text { تشكر و قدردانى }
$$

اين مطالعه بطور كلى با حمايت مالى و معنوى معاونت

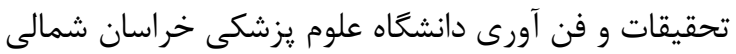

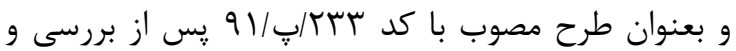
تائيد در كميته اخلاق همان دانشعاه انجام گرفته است. در يايان نويسندكان از مسئولين و يرسنل محترم اورزانس

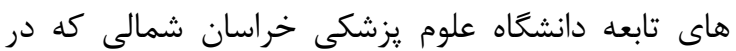
انجام اين تحقيق صميمانه همكارى نموده اند تشكر مى نى نمائيم.

\section{References}

1. Zohoor AR, Pilevar Zadeh M, Study of speed of offering services in emergency department at kerman bahonar hospital in 2000, iran medical journal 2002;10(35):413420[Persian].

2. Hassani SA, masoumi gh, shahrami A, muhammadi R, Gholsmpour M, Heidari A, Standardization of medical emergencies in hospitals, first edition, Tehran, Simin Press Coverage ,2010; p:13[Persian].

3. Ahmadi Amoli H, Tavakkoli $\mathrm{H}$, Khashayar P, Panahi F, Alavi Moghaddam M, Ahmadi Amoli M, The Efficacy of Pre-Hospital Care in Traumatic Patients referred to Emergency Ward of "Sina Hospital" between September 2003 and September 2004,pejouhandeh shahid
نتيجه راديوگرافى حداكثر لها دقيقه ييش بينى شده است

وضعيت مطلوبى دارد. [ [10]

همجنين در مقايسه با مطالعات مشابه نظير مطالعه نظميه

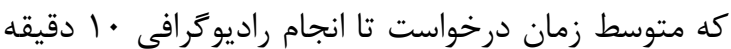
بوده و در مطالعه ظهور و همكاران كه اين فاصله درخواست راديولوزى تا دريافت نتيجه هان دقيقه بوده است كمترين اتلاف زمان را به خود اختصاص داده است.

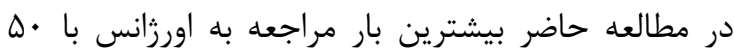

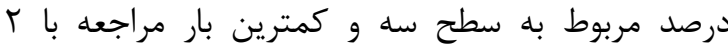
درصد مربوط به سطح يك بوده است. كثرت مراجعين

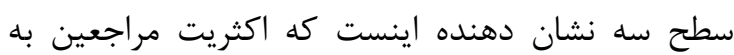
اورزانس هاى بيمارستانى، حداقل از دو مورد از تسهيلات

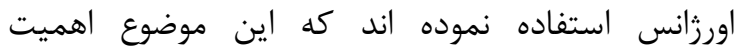

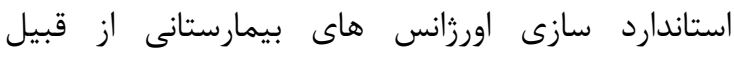
اختصاص نيروى انسانى كافى و متبحر به اورزانس و خدمات ياراكلينيكى خاص اورزانس از قبئ آنيل آزمايشعاه اورزانس، راديولوزى اورزانس را بيان مى نمايد. همجنين با آناريا

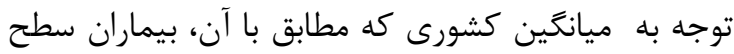
يك مى تواند ا تا بّ/ بيماران اورزانس را شامل شوند، بار مراجعات سطح يك در اورزانس هاى مورد مطالعه از

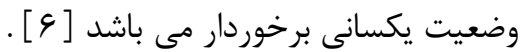

beshti university of medical sciences;13(3):203-212[Persian].

4. Mohkam M, Saiiari A, Imanzadeh F, Asgarian F, Ghoroubi J, Hatamian B, Ghorgi $\mathrm{F}$, Comparison of Emergency Wards in University-Affiliated Hospitals with Iranian Ministry of Health Standards, Shahid Beheshti University of Medical Sciences, 2009;14(2):77-81[Persian].

5. Dehnadi moghadam A,Yousef zade chabok Sh, Hemati H, Shabani S, comparison the number of triaged in three working shift in poursina hospital in rasht, Journal Of Guilan University Of Medical Sciences 2008;17(65):68-76[Persian].

6. Afzalimoghadam $M$, Hoseinnejad $H$, Seyed hoseini J, Seyed hoseini davarani $\mathrm{H}$, 
handbook of hospital workshop with ESI method ,fourt edition.tehran university of medical sciences 2011: 4-5[Persian].

7. Tabibi SJ, Najafi B, Shoaie Sh, Waiting time in the emergency department in selected hospitals of Iran University of Medical Sciences in 2007;33(2):117-122[Persian].

8. Moghadesi $\mathrm{H}$, statistics in medical management, first edition, Tehran, word processors, 2002; p: 74[Persian].

9. Hatamabadi $\mathrm{H}$, Mohammadi A, Reasons for Long-Stay Admission in a Typical Overcrowded Emergency of A Teaching Hospital in Tehran Capital City, pejouhandeh, shahid beshti university of medical sciences;13(1):71-75[Persian].

10.Liew D, Kennedy MP, Emergency department length of stay independently predicts excess inpatient length of stay, Med J Aust 2003;179(10):524-526
11.Hafezi Moghadam P, Ayoubi A, Study of waiting time for emergency visits to hospital emergency departments Prophet in the first quarter of 2009, Fourth National Conference on Emergency Medicine 2009:38-39 [Persian]. 12.Little JM, Health care rationing constraints and equity, Med J Aust 2001;174(12).641-642 13.Salluzor R, Mayer T, editors, Emergency department management principles and applications.st.louis:mosby.1997

14. Nazmiyeh H, Dehghani A, Timing of emergency services provision by using triage form in Yazd hospital, May 2006, The Third International Congress on health and disaster management disaster[Persian].

15. Gold frank L, Henneman PL, Ling LJ, Prescott JG, Rosen C, Sama A, Emergency center categorization standards, academic emergency medical 1999;17(8):638-655 


\title{
Study of speed of offering services in the educational hospitals of North Khorasan University of Medical Sciences in 2011
}

\author{
Jafakesh mogadam $A^{1 *}$, Pournaghi $S J^{2}$, Masoumi $M^{3}$, Hashemi $M^{4}$, Vafaei $T^{5}$, neyestani $H^{6}$
}

\author{
${ }^{1}$ B.Sc of nursing, Deputy of treatments, North Khorasan University of Medical Sciences, Bojnurd, Iran \\ ${ }^{2}$ Assistant professor of gastroenterology, Deputy of treatment, North Khorasan University of Medical Sciences, \\ Bojnurd, Iran \\ ${ }^{3}$ B.Sc of nursing, Emam Reza hospital, North Khorasan University of Medical Sciences, Bojnurd, Iran \\ ${ }^{4}$ M.Sc of statistics, Deputy of research, North Khorasan University of Medical Sciences, Bojnurd, Iran \\ ${ }^{5}$ M.Sc of nursing, Deputy of treatments, North Khorasan University of Medical Sciences, Bojnurd, Iran \\ ${ }^{6}$ B.Sc of nursing, Emam Ali hospital, North Khorasan University of Medical Sciences, Bojnurd, Iran
}

\begin{abstract}
*Corresponding Author: Deputy of treatments, North Khorasan University of Medical Sciences, Bojnurd, Iran

Email: jafakesh.as@gmail.com
\end{abstract}

Abstract
Background and objectives: The speed of the offered services in
treatment centers, especially emergency, has a great importance
in reducing mortality rate. If treatment process takes a long time
in emergency units, it shows there is no discipline in general
planning, practical instruction and hospitals current affairs. This
study was done based on the importance of this issue with the aim
of increasing speed of servicing in educational hospitals of north
Khorasan University of Medical Sciences In 2011
Materials and Methods: This descriptive study was conducted in
a period of one month .1066 standard forms were selected by
proportional stratified random sampling in emergency unit
services and the collected data were analyzed by SPSS software
15 and presented with one-way ANOVA.
Results: the findings of the study in five hospitals revealed that
the average spent time of each item was as follow: patient
entrance to physician office: 6 min, the average time for first
treatment act: 5 min, the average time for lab testing till result 77
min, radiology and the result 7 min, CT scan 24 min, and the
time of ECG 3 min
Conclusion: All under studied cases had a good servicing rate
but the result for tests had a little difference with international
and country standards. Based on the importance of indices in
making decision for releasing patients from hospitals, it is
recommend adopting strategies in hospital management to
reduce offered services intervals
Key words: Time evaluation, emergency unit, time residency
ing

Abstract treatment centers, especially emergency, has a great importance in reducing mortality rate. If treatment process takes a long time in emergency units, it shows there is no discipline in general planning, practical instruction and hospitals current affairs. This study was done based on the importance of this issue with the aim of increasing speed of servicing in educational hospitals of north Khorasan University of Medical Sciences In 2011 a period of one month 1066 standard forms were selected by proportional stratified random sampling in emergency unit services and the collected data were analyzed by SPSS software 15 and presented with one-way ANOVA.

Results: the findings of the study in five hospitals revealed that the average spent time of each item was as follow: patient entrance to physician office: $6 \mathrm{~min}$, the average time for first treatment act: $5 \mathrm{~min}$, the average time for lab testing till result 77 min, radiology and the result 7 min, CT scan 24 min, and the time of ECG 3 min

Conclusion: All under studied cases had a good servicing rate but the result for tests had a little difference with international making decision for releasing patients from hospitals, it is recommend adopting strategies in hospital management to Key words: Time evaluation, emergency unit, time residency

Submitted:2013 Feb 6

Revised:2013 Aug 25

Accepted: 2013 Sep 7 